\title{
Photoinduced electron transfer processes of (E)-9-(4-nitrostyryl)anthracene in non-polar solvent medium: generation of long-lived charge-separated states ${ }^{\S}$
}

\author{
AYAN BHATTACHARYYA, SWATILEKHA PRATIHAR and EDAMANA PRASAD* \\ Department of Chemistry, Indian Institute of Technology Madras, Chennai 600 036, Tamil Nadu, India \\ E-mail: pre@iitm.ac.in
}

MS received 10 August 2018; revised 3 September 2018; accepted 4 September 2018; published online 29 September 2018

\begin{abstract}
In the present study, photoinduced electron transfer (PET) dynamics between N,N-diethylaniline (DEA) and (E)-9-(4-nitrostyryl)anthracene $\left(\mathrm{An}-\mathrm{NO}_{2}\right)$ in a non-polar solvent medium \{methylcyclohexane $(\mathrm{MCH})\}$, has been investigated. The rate constant of back electron transfer $\left(\mathrm{k}_{\mathrm{BET}}\right)$ for the $\mathrm{An}-\mathrm{NO}_{2}-\mathrm{DEA}$ pair was $\sim 3.8 \times 10^{5} \mathrm{~s}^{-1}$ which is $c a .2$ orders of magnitude less compared to the anthracene (An)-DEA (control) system. The results indicate that long-lived charge separated species can be generated using the design strategy used herein by achieving resonance stabilization of the excited state (acceptor) radical via conjugation.
\end{abstract}

Keywords. Photoinduced electron transfer; $\pi$-conjugated system; back electron transfer; long-lived chargeseparated states.

\section{Introduction}

In the past decades, organic donor - acceptor (D-A) molecules have attracted significant attention due to their potential applications in photovoltaic cells and optoelectronic devices. ${ }^{1-5}$ For such applications, there is a need for designing donor-acceptor systems that would hinder charge-recombination upon photoexcitation, ${ }^{6,7}$ so that the back electron transfer process is slowed down leading to the generation of long-lived charge separated states. Long-lived charge separated species find their applications in various emerging fields of research such as solar cells, energy conversions and heterogeneous photocatalysis. ${ }^{8-10}$

Charge-separated species viz., radical cations and radical anions are the primary photoproducts generated via intra- as well as inter-molecular photoinduced electron transfer (PET) processes. ${ }^{11-14}$ An important and challenging area of research in this field is to devise strategies for stabilizing the charge-separated states formed via PET processes. Reports show that bimolecular PET processes carried out in constrained media like micelles and zeolites, generate long-lived charge separated states owing to the reduced rate of back electron transfer. ${ }^{15,16}$ In a similar way, designing of dyad or triad systems with proper structural attributes have been found to significantly lower the rate of intramolecular back electron transfer. ${ }^{17}$

That extended conjugation in a molecule enhances resonance stabilization of a radical center in it, is a known concept in chemistry. Thus we propose that the radical anion generated via transfer of electron from donor to acceptor, would be stable if the acceptor system has an extended $\pi$-conjugation that is capable of de-localizing the negative charge within the molecule via a 'push-pull' mechanism. In a recent work from our group, we have established this hypothesis for two highly conjugated derivatives of pyrene and anthracene, namely (E)-4-(2-(pyren-1-yl)vinyl)benzonitrile (PyCN) and (E)-4-(2-(anthracen-9-yl)vinyl)benzonitrile (An $\mathrm{CN}){ }^{18}$ In the present work, we extend this particular hypothesis to another extremely well-studied organic

\footnotetext{
*For correspondence

$\S$ Dedicated to Professor M V George on the occasion of his $90^{\text {th }}$ Birth Anniversary.
}

Electronic supplementary material: The online version of this article (https://doi.org/10.1007/s12039-018-1555-8) contains supplementary material, which is available to authorized users. 
D- $\pi-A$ system namely, (E)-9-(4-nitrostyryl)anthracene $\left(\mathrm{An}-\mathrm{NO}_{2}\right) .{ }^{19-23}$ We hypothesize that $\mathrm{An}-\mathrm{NO}_{2}$ as an electron acceptor can generate long-lived charge separated species via PET due to the increased feasibility of charge delocalization in it.

It is well known that in highly non-polar solvent medium like hexane and methylcyclohexane $(\mathrm{MCH})$, An- $\mathrm{NO}_{2}$ emits from its excited singlet state $\left(\mathrm{S}_{1}\right)$, whereas with slight increase in solvent polarity, significant intramolecular charge transfer (ICT) occurs in the excited state. ${ }^{19-23}$ In order to avoid any discrepancies arising from structural distortions in the excited state due to ICT, we have carried out the PET studies in methylcyclohexane $(\mathrm{MCH})$. Steady state and time resolved luminescence quenching studies have been carried out to determine the bimolecular quenching constant $\left(\mathrm{k}_{\mathrm{q}}\right)$. Nanosecond laser flash photolysis experiments have been carried out to verify the formation of the transient radical ions and to determine the rate constant of back electron transfer. The obtained results have been compared with that of the anthracene (An) - DEA system.

\section{Experimental}

\subsection{Materials}

All commercially available reagents and solvents were used without further purification. 4-nitrobenzyl bromide and all UV-grade solvents (i.e., methylcyclohexane and THF) were bought from Spectrochem Pvt. Ltd, India. Triphenylphosphine and 9-anthracenecarboxaldehyde were bought from Sigma Aldrich (U.S.A). Potassium tertiary butoxide was obtained from Avra Synthesis Pvt. Ltd., India. N, N-diethylaniline was bought from Merck. Reactions were carried out in oven-dried glassware (i.e., round bottom flasks, vials, and NMR tubes) under nitrogen atmosphere.

\subsection{UV-visible absorption studies}

A JASCO V-660 spectrophotometer was used for carrying out the UV-visible absorption studies. All samples were taken in a square-shaped two-faced transparent quartz cuvette having a path length of $1 \mathrm{~cm}$. All the experiments were carried out at ambient temperature. Concentration dependent UV-visible experiments were carried out keeping the concentration of An- $\mathrm{NO}_{2}$ constant at $40 \mu \mathrm{M}$ while the concentration of DEA was varied in between $0.024 \mathrm{M}-0.168 \mathrm{M}$.

\subsection{Steady state luminescence experiments}

All the steady state luminescence experiments were carried out in a Horiba Jobin Yvon Fluoromax-4 instrument using a four-side transparent quartz cuvette. Luminescence quenching experiments were carried out with a series of DEA solutions with varying concentrations $(0.024 \mathrm{M}$ to $0.168 \mathrm{M})$, keeping the excitation/emission slit widths at $2 / 2$.

\subsection{Time-resolved luminescence decay measurements}

Time resolved luminescence measurements were carried out in a Horiba Jobin Yvon Fluorocube instrument in a time correlated single photon counting (TCSPC) arrangement using a $405 \mathrm{~nm}$ LED with a pulse repetition rate of $1 \mathrm{MHz}$ as the light source. The Instrument Response Function (IRF) was collected using a scatterer (Ludox AS40, colloidal silica, Sigma Aldrich). The full width at half maximum for the $405 \mathrm{~nm}$ LED light source is approximately $0.5 \mathrm{~ns}$ including detector response. The wavelength was fixed at near the emission maximum and the excited state decay of the samples was collected and the decay was fitted using the IBH software DAS6 according to the following equation:

$I(t)=\Sigma A_{i} \exp \left(-t / \tau_{i}\right)$

$\tau_{\mathrm{i}}=$ luminescence lifetime, $\mathrm{A}_{\mathrm{i}}=$ the amplitude of the corresponding decay.

\subsection{Laser flash photolysis studies}

Transient absorption spectra (TAS) were recorded using a nanosecond laser flash photolysis instrument (Applied Photophysics, U.K.). To photo excite the samples, the third harmonic of a Q-switched Nd: YAG laser (Quanta Ray, Lab 150, Spectra Physics, USA) was used. The signals from the transients were probed using a $150 \mathrm{~W}$ pulsed xenon lamp, a Czerny - Turner monochromator, and Hamamatsu R-928 photomultiplier tube as a detector. The pulse width of the laser light was $8 \mathrm{~ns}$. The transient signals were captured using an Agilent infiniium digital storage oscilloscope followed by the transfer of all the data to the computer for further analysis. Before recording the TAS the samples were purged with Argon gas for 30 minutes.

\section{Results and Discussion}

The structure of the aromatic amine $\{\mathrm{N}, \mathrm{N}$-diethylaniline (DEA) $\}$ and the conjugated anthracene derivative, (E)9-(4-nitrostyryl)anthracene $\left\{\mathrm{An}-\mathrm{NO}_{2}\right\}$ is shown in Chart 1 . The synthesis details and scheme for $\mathrm{An}-\mathrm{NO}_{2}$ has been provided in the Supplementary Information along with the characterization $\left({ }^{1} \mathrm{H},{ }^{13} \mathrm{C}\right.$ and HRMS) data of An- $\mathrm{NO}_{2}$ (Scheme S1 1.1, Supplementary Information).

\subsection{Steady-state luminescence quenching studies}

In $\mathrm{MCH}, \mathrm{An}-\mathrm{NO}_{2}$ exhibits a structured absorption spectrum with the maxima around $390 \mathrm{~nm}$. Upon addition of DEA, the absorbance maxima did not show any shift. Further, no changes were observed in the 
<smiles>O=[N+]([O-])c1ccc(/C=C/c2c3ccccc3cc3ccccc23)cc1</smiles><smiles>CCN(CC)c1ccccc1</smiles>

Chart 1. The structure of the electron acceptor (E)-9-(4nitrostyryl)anthracene $\left(\mathrm{An}-\mathrm{NO}_{2}\right)$ on the left and the structure of the electron donor N,N-diethylaniline (DEA) on the right.

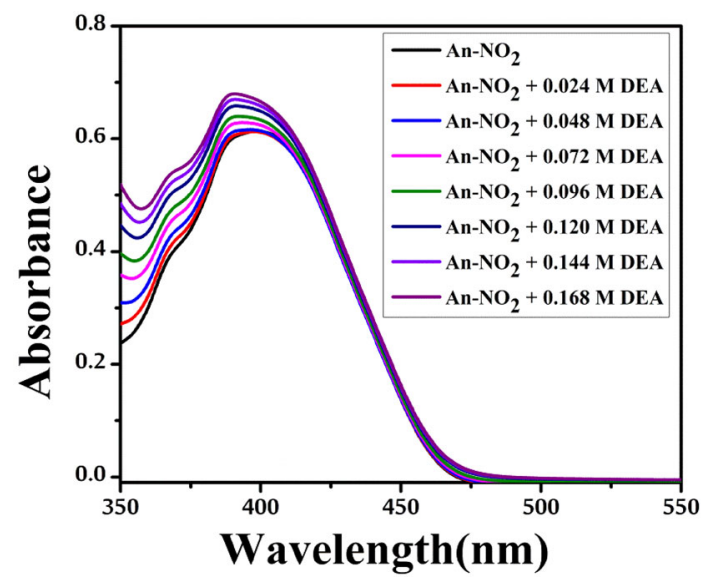

Figure 1. The UV-Visible absorption spectra of An- $\mathrm{NO}_{2}[40 \mu \mathrm{M}]$ with increasing concentration of N,N-diethylaniline (DEA) [0.024 M-0.168 M] in methylcyclohexane $(\mathrm{MCH})$.

shape of the absorption spectrum upon addition of DEA (Figure 1). The small enhancement in absorbance in the region $\leq 425 \mathrm{~nm}$ is due to the absorbance of the quencher DEA. Thus, we conclude that there is no significant interaction between the donor and the acceptor molecule in their ground state.

When excited at $400 \mathrm{~nm}, \mathrm{An}-\mathrm{NO}_{2}$ exhibits an emission maximum around $505 \mathrm{~nm}$. Upon addition of the quencher DEA, the emission intensity reduced significantly suggesting a strong interaction between excited singlet $\mathrm{S}_{1}$ state of $\mathrm{An}-\mathrm{NO}_{2}$ with the amine, DEA (Figure 2). It is to be noted that no exciplex emission has been observed upon addition of the quencher, which is in contrast to the control system viz., anthracene (An) - DEA in non-polar solvents. ${ }^{24,25}$

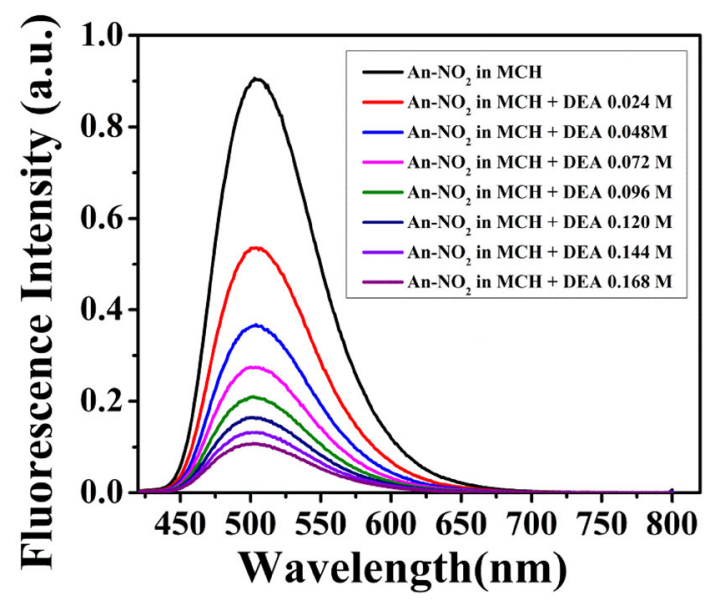

Figure 2. The steady-state luminescence quenching studies of $\mathrm{An}-\mathrm{NO}_{2}\left[\begin{array}{ll}40 & \mu \mathrm{M}\end{array}\right]$ in methylcyclohexane $(\mathrm{MCH})$ with increasing concentration of the quencher $\mathrm{N}, \mathrm{N}$-diethylaniline (DEA) $[0.024 \mathrm{M}-0.168 \mathrm{M}]$. The excitation wavelength $\left(\lambda_{\mathrm{ex}}\right)=400 \mathrm{~nm}$. [Note: no red-shifted band has been observed with increased DEA concentration showing that no exciplex formation has taken place upto this particular concentration of DEA].

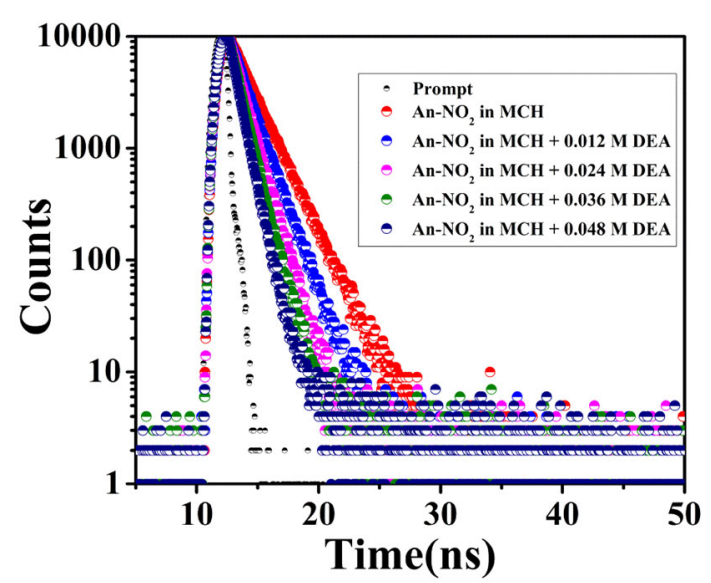

Figure 3. The time-resolved luminescence quenching studies of $\mathrm{An}-\mathrm{NO}_{2}\left[\begin{array}{ll}40 & \mu \mathrm{M}\end{array}\right]$ in methylcyclohexane $(\mathrm{MCH})$ with increasing concentration of the quencher; N,N-diethylaniline (DEA) [0.012 M-0.048 M]. The excitation wavelength $\left(\lambda_{\text {ex }}\right)$ is $405 \mathrm{~nm}$. The collection wavelength $\left(\lambda_{\text {coll }}\right)$ is $500 \mathrm{~nm}$.

\subsection{Time-resolved luminescence quenching studies}

An- $\mathrm{NO}_{2}$ exhibits a lifetime of $1.8 \mathrm{~ns}$ in $\mathrm{MCH}$ which reduces significantly on addition of the quencher. The lifetime decay profiles are given in Figure 3 and the lifetime quenching data is summarized in Table 1.

From the steady-state luminescence quenching studies, we rule out the possibility of resonance energy 
Table 1. Luminescence lifetime values of $\mathrm{An}-\mathrm{NO}_{2}$ in presence of various concentrations of DEA $(0.012 \mathrm{M}-0.048 \mathrm{M})$, $\lambda_{\mathrm{ex}}=405 \mathrm{~nm}, \lambda_{\text {coll }}=500 \mathrm{~nm}$.

\begin{tabular}{lcc}
\hline$[\mathrm{DEA}](\mathrm{M})$ & $\tau$ (in ns) & $\chi^{2}$ \\
\hline 0 & 1.80 & 1.03 \\
0.012 & 1.36 & 1.02 \\
0.024 & 1.08 & 1.03 \\
0.036 & 0.90 & 1.07 \\
0.048 & 0.74 & 1.20 \\
\hline
\end{tabular}

transfer from excited $\mathrm{An}-\mathrm{NO}_{2}$ to DEA since there is no significant overlap between the emission spectrum of An- $\mathrm{NO}_{2}$ and absorption spectrum of DEA. Since DEA is a tertiary amine the possibility of an excited state proton transfer can also be ruled out. The results taken together point towards the fact that the observed luminescence quenching is due to PET.

\subsection{Stern-Volmer analysis}

The steady-state (SS) and time-resolved (TR) Stern-Volmer plots for the An- $\mathrm{NO}_{2}$ and DEA pair was plotted and the quenching constant $\left(\mathrm{k}_{\mathrm{q}}\right)$ was determined. The plots have been presented as Figures S1 and S2, Supplementary Information. The comparable $\mathrm{k}_{\mathrm{q}}$ values (within the range of experimental error) obtained in the SS and TR Stern Volmer analysis viz. $2.2 \times 10^{10} \mathrm{M}^{-1} \mathrm{~s}^{-1}$ and $1.6 \times 10^{10} \mathrm{M}^{-1} \mathrm{~s}^{-1}$, respectively, asserts the dynamic nature of the quenching. Further, it is known that the value of $\mathrm{k}_{\mathrm{q}}$ lies in the range of $10^{9}-10^{10} \mathrm{M}^{-1} \mathrm{~s}^{-1}$ in the diffusion-controlled regime. ${ }^{26}$ Thus, we conclude that the observed luminescence quenching of $\mathrm{An}-\mathrm{NO}_{2}$ is diffusion-controlled.

\subsection{Calculation of the free energy change associated} with forward electron transfer (PET) and back electron transfer (BET) processes

To realize the thermodynamic feasibility of the forward electron transfer process (PET) between DEA and $\mathrm{An}-\mathrm{NO}_{2}$, the free energy of PET $\left(\Delta \mathrm{G}_{\mathrm{PET}}\right)$ has been calculated using the oxidation potential of the donor (DEA) and reduction potential of the acceptor $\left(\mathrm{An}-\mathrm{NO}_{2}\right)$. The oxidation potential of DEA in acetonitrile has been obtained from literature ${ }^{27,28}$ and reduction potential of An- $\mathrm{NO}_{2}$ was determined in acetonitrile [Figure S3, Supplementary Information] and those values have been utilized to evaluate the free energy of PET in methylcyclohexane according to the modified Rehm-Weller equation. ${ }^{29}$

$\Delta G_{P E T}=E^{0}\left(D^{+} / D\right)-E^{0}\left(A / A^{-}\right)-E^{00}$

$$
\begin{aligned}
& -\left[\frac{e^{2}}{2 * 4 \pi \varepsilon_{0}}\left(\frac{1}{r_{D}}+\frac{1}{r_{A}}\right)\left(\frac{1}{37}-\frac{1}{\varepsilon_{s}}\right)\right] \\
& -\frac{e^{2}}{4 \pi \varepsilon_{0} d_{c c}}
\end{aligned}
$$

where, $\mathrm{E}^{0}\left(\mathrm{D}^{+} / \mathrm{D}\right)=0.76 \mathrm{~V}\left[\mathrm{vs} \mathrm{Ag} / \mathrm{Ag}^{+}\right.$(satd. $\left.\left.\mathrm{KCl}\right)\right]$ and $\mathrm{E}^{0}\left(\mathrm{~A} / \mathrm{A}^{-}\right)=-1.25 \mathrm{~V}\left[\mathrm{vs} \mathrm{Ag} / \mathrm{Ag}^{+}\right.$(satd. $\mathrm{KCl}$ )] are the oxidation potential of the donor and reduction potential of the acceptor, respectively (in acetonitrile), $\mathrm{E}^{00}=$ the singlet energy of the acceptor $=2.68 \mathrm{eV}$, $\mathrm{e}=$ charge of an electron $=1.602 \times 10^{-19} \mathrm{C}, \varepsilon_{0}=$ permittivity of free space, $\varepsilon_{\mathrm{s}}=$ dielectric constant of the solvent where we want to measure the feasibility of electron transfer (methylcyclohexane with $\varepsilon_{\mathrm{s}}=2.02$ ), $\mathrm{r}_{\mathrm{D}}=0.4 \mathrm{~nm}$ and $\mathrm{r}_{\mathrm{A}}=0.6 \mathrm{~nm}$ are the radii of the donor and acceptor, respectively, and $\mathrm{d}_{\mathrm{cc}}=$ the centre to centre distance of the donor and the acceptor in the encounter complex $\left(d_{c c} \sim r_{D}+r_{A}\right)$. The $E^{00}$ value for An- $\mathrm{NO}_{2}$ was calculated from the point of intersection of the absorption and emission spectrum. The calculated $\Delta \mathrm{G}_{\mathrm{PET}}$ value was negative viz. $-0.73 \mathrm{eV}$ which explains the feasibility of the PET process.

Additionally, we calculated the driving force for the back electron transfer process $\left(\Delta \mathrm{G}_{\mathrm{BET}}\right)$ viz. $-1.95 \mathrm{eV}$ utilizing the value of $\mathrm{E}^{00}$ and $\Delta \mathrm{G}_{\mathrm{PET}}$ according to the following formula: ${ }^{30,31}$

$\Delta \mathrm{G}_{\mathrm{BET}}=-\mathrm{E}^{00}-\Delta \mathrm{G}_{\mathrm{PET}}$

In order to observe the formation of the charge separated states via PET, nanosecond laser flash photolysis experiments were carried out.

\subsection{Laser flash photolysis studies}

The transient absorption spectrum of $\mathrm{An}-\mathrm{NO}_{2}[40 \mu \mathrm{M}]$ in $\mathrm{MCH}$ exhibits two sharp peaks centered at $520 \mathrm{~nm}$ and $540 \mathrm{~nm}$ with a lifetime of $1.8 \pm 0.1 \mu \mathrm{s}$. These two peaks are assigned to the $\mathrm{T}_{1}-\mathrm{T}_{\mathrm{n}}$ transitions of $A n-\mathrm{NO}_{2}$ in $\mathrm{MCH}$. The decay rate constant for the $\mathrm{T}_{1}-\mathrm{T}_{\mathrm{n}}$ transition is ca. $5.5 \times 10^{5} \mathrm{~s}^{-1}$ (Figure 4).

The TAS spectral envelope of An- $\mathrm{NO}_{2}$ changes in presence of the quencher DEA [0.168 M] wherein, it exhibits two sharp peaks centered around $460 \mathrm{~nm}$ and $510 \mathrm{~nm}$, respectively. These peaks exhibit a lifetime of $2.6 \pm 0.1 \mu \mathrm{s}$. Based upon literature, we can assign the $460 \mathrm{~nm}$ peak to the DEA radical cation. ${ }^{18,32}$ Thus, the $510 \mathrm{~nm}$ peak is supposedly due to the $\mathrm{An}-\mathrm{NO}_{2}$ radical anion. The decay rate constants corresponding to the transient lifetimes of the ion-pair is roughly equal and is $\sim 3.8 \times 10^{5} \mathrm{sec}^{-1}$. We assign the decay rate constants as the rate constant for back electron transfer $\left(\mathrm{k}_{\mathrm{BET}}\right)$ considering the ion-pairs do not participate in any other excited state processes. It is to be noted 


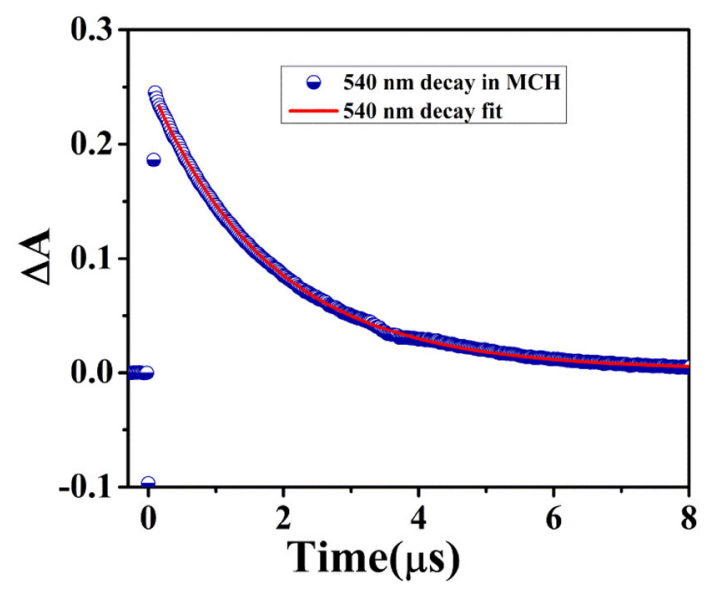

Figure 4. The $540 \mathrm{~nm}$ decay of $\mathrm{An}-\mathrm{NO}_{2}$ in $\mathrm{MCH}$ $\left(\lambda_{\text {ex }}=355 \mathrm{~nm}\right)$ revealing a $\mathrm{T}_{1}-\mathrm{T}_{\mathrm{n}}$ decay rate constant of $\sim 5.5 \times 10^{5} \mathrm{~s}^{-1}$.

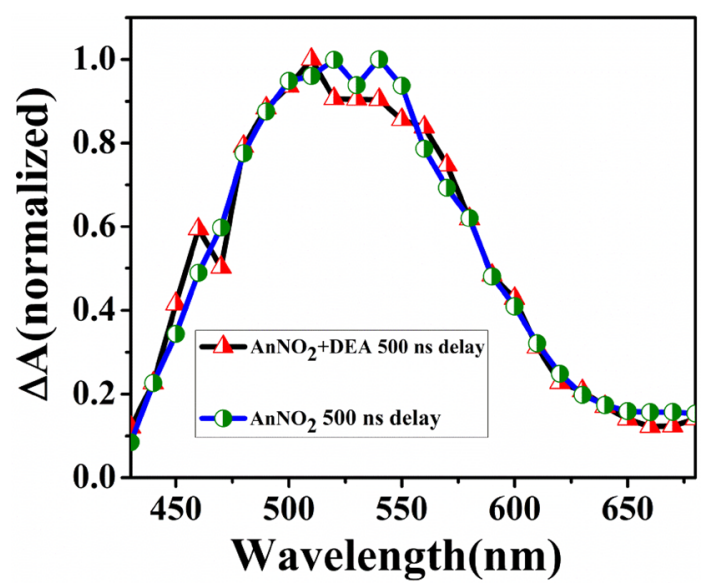

Figure 5. The normalized $\triangle \mathrm{A}$ spectrum for $\mathrm{An}-\mathrm{NO}_{2}[40 \mu \mathrm{M}]$ and An-NO $2+$ DEA [0.168 M] at 500 ns delay clearly revealing the change in the TA spectral profile. The former spectrum reveals two peaks centered around $540 \mathrm{~nm}$ and $520 \mathrm{~nm}$ which can be assigned as the $T_{1}-T_{n}$ transitions of An- $\mathrm{NO}_{2}$. In presence of DEA, the later spectrum reveals two peaks at $510 \mathrm{~nm}$ and $460 \mathrm{~nm}$ which can be assigned as the $\mathrm{An}-\mathrm{NO}_{2}$ radical anion and DEA radical cation, respectively.

that the formula $\mathrm{k}_{\mathrm{BET}}=1 / \tau_{\text {radical }}$ has been used for the calculation of the back electron transfer rate constant value. Figure 5 shows the $\triangle \mathrm{A}$ normalized spectra of $\mathrm{An}-\mathrm{NO}_{2}$ in $\mathrm{MCH}$ at $500 \mathrm{~ns}$ delay, in the presence and absence of DEA, clearly revealing the differences. Figure 6 shows the $510 \mathrm{~nm}$ decay for $\mathrm{An}-\mathrm{NO}_{2}+\mathrm{DEA}$ system. It is to be noted that in presence of DEA, the $\triangle A$ values for the $T_{1}-T_{n}$ transitions significantly reduces which also enunciates a significant excited state interaction between $\mathrm{An}-\mathrm{NO}_{2}$ and DEA leading to a reduction in the triplet population.

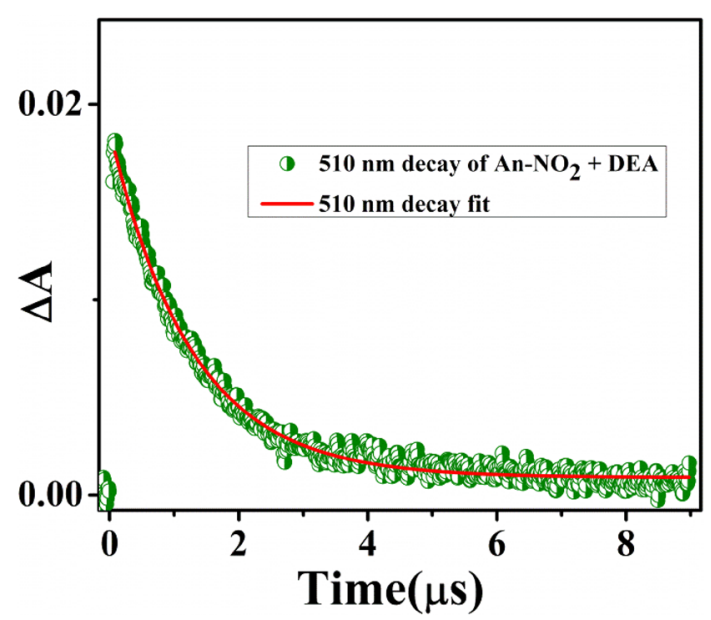

Figure 6. The $510 \mathrm{~nm}$ decay of $\mathrm{An}-\mathrm{NO}_{2}+\mathrm{DEA}$ revealing a back electron transfer rate constant $\left(\mathrm{k}_{\mathrm{BET}}\right)$ of $3.8 \times 10^{5} \mathrm{~s}^{-1}$.

Similar experiments with the control system An-DEA in $\mathrm{MCH}$, revealed the growth of a new band around $350-370 \mathrm{~nm}$. From literature reports, this band can be assigned as the anthracene radical anion. ${ }^{33,34}$ The calculated rate constant for the back electron transfer process for An-DEA was found to be $\left(\sim 1 \times 10^{7} \mathrm{sec}^{-1}\right)$, which is significantly faster compared to our system. The transient absorption spectra of anthracene in presence and absence of DEA has been shown (Figures S4-S5, Supplementary Information). The $350 \mathrm{~nm}$ decay fit has been shown in Figure S6 (Supplementary Information).

The free-energy change for the BET process for An-DEA is $-1.35 \mathrm{eV}$ whereas for $\mathrm{An}-\mathrm{NO}_{2}$ it is $-1.95 \mathrm{eV}$ (Table 2). In terms of the energetics of the back electron transfer process, $\mathrm{k}_{\mathrm{BET}}\left(\mathrm{An}-\mathrm{NO}_{2}+\mathrm{DEA}\right)$ should be higher than $\mathrm{k}_{\mathrm{BET}}(\mathrm{An}+\mathrm{DEA})$. Thus, we conclude that the BET process is not activation controlled. The enhanced stability of the charge-separated states for the $\mathrm{An}-\mathrm{NO}_{2}$-DEA pair is attributed to the increased stability of the An- $\mathrm{NO}_{2}$ radical anion (compared to the anthracene radical anion) via delocalization of the charge over the extended $\pi$-conjugated structure.

Additionally, PET studies of An- $\mathrm{NO}_{2}$ and DEA has been carried out in a relatively polar solvent tetrahydrofuran (THF). The results have been presented in the supplementary information (Figures S7-S11). Since, in THF, An- $\mathrm{NO}_{2}$ emits from the ICT state and not from its excited singlet state as in $\mathrm{MCH}$, no comparison of the PET dynamics has been done with the control molecule anthracene. However, the $\mathrm{k}_{\mathrm{BET}}$ value has been calculated which is $\sim 1.36 \times 10^{5} \mathrm{~s}^{-1}$ which is slightly less compared to the $\mathrm{k}_{\mathrm{BET}}$ value in $\mathrm{MCH}$. This shows that with 
Table 2. The tabulated parameters viz. $\mathrm{E}^{00}, \mathrm{r}_{\mathrm{D}}, \mathrm{r}_{\mathrm{A}}, \mathrm{d}_{\mathrm{cc}}, \Delta \mathrm{G}_{\mathrm{PET}}, \Delta \mathrm{G}_{\mathrm{BET}}, \mathrm{k}_{\mathrm{BET}}$ for An- $\mathrm{NO}_{2}-\mathrm{DEA}$ and anthracene (An)-DEA.

\begin{tabular}{lccccccc}
\hline System & $\mathrm{E}^{00}(\mathrm{eV})$ & $\mathrm{r}_{\mathrm{D}}(\mathrm{nm})$ & $\mathrm{r}_{\mathrm{A}}(\mathrm{nm})$ & $\mathrm{d}_{\mathrm{cc}}(\mathrm{nm})$ & $\Delta \mathrm{G}_{\mathrm{PET}}(\mathrm{eV})$ & $\Delta \mathrm{G}_{\mathrm{BET}}(\mathrm{eV})$ & $\mathrm{k}_{\mathrm{BET}}\left(\mathrm{s}^{-1}\right)$ \\
\hline An- $\mathrm{NO}_{2}$ and DEA & 2.68 & 0.40 & 0.60 & 1.0 & -0.73 & -1.95 & $3.8 \times 10^{5}$ \\
Anthracene and DEA & 3.30 & 0.40 & 0.46 & 0.85 & -1.95 & -1.35 & $1 \times 10^{7}$ \\
\hline
\end{tabular}

increase in solvent polarity, the solvation of the radical species gets enhanced, leading to a greater stabilization of the charge-separated states.

\section{Conclusions}

The photoinduced electron transfer from $\mathrm{N}$, N-diethylaniline (DEA) to (E)-9-(4-nitrostyryl) anthracene $\left(\mathrm{An}-\mathrm{NO}_{2}\right)$ in a non-polar solvent medium viz. methylcyclohexane $(\mathrm{MCH})$ has been studied. It has been observed that the luminescence quenching is diffusion-controlled. Unlike anthracene, no exciplex formation has been observed for $\mathrm{An}-\mathrm{NO}_{2}$. The radical ion species formed as a result of the PET process has been assigned. The rate constant for the back electron transfer process $\left(\mathrm{k}_{\mathrm{BET}}\right)$ has been calculated using the formula $\mathrm{k}_{\mathrm{BET}}=1 / \tau_{\text {radical }}$. It has been observed that the rate constant for the back electron transfer process is $\sim 2$ orders of magnitude slower in case of $\mathrm{An}-\mathrm{NO}_{2} / \mathrm{DEA}$ when compared with anthracene/DEA. We conclude that the presence of extended $\pi$-conjugated structure leads to efficient delocalization of charge in case of An- $\mathrm{NO}_{2}$, thus generating long-lived charge separated states via intermolecular PET processes.

\section{Supplementary Information (SI)}

The synthesis and characterization data of $\mathrm{An}-\mathrm{NO}_{2}$ viz., ${ }^{1} \mathrm{H}-\mathrm{NMR},{ }^{13} \mathrm{C}-\mathrm{NMR}$ and HR-MS spectra; the steady-state and time-resolved Stern-Volmer plots; the cyclic voltammetry study of $\mathrm{An}-\mathrm{NO}_{2}$ in acetonitrile; the $\Delta \mathrm{A}$ vs wavelength plot for anthracene in the absence and in presence of DEA; $\triangle \mathrm{A}$ vs time plot for the BET rate constant for An-DEA system; PET data for An-NO $\mathrm{N}_{2}$ - DEA in THF; excitation spectra of An- $\mathrm{NO}_{2}$ in the absence and in presence of DEA. Supplementary Information is available at www.ias.ac.in/chemsci.

\section{Acknowledgements}

A.B. and S.P. are grateful to the Ministry of Human Resource and Development (MHRD) and IIT Madras for fellowships. E.P. acknowledges the Solar Energy Research Initiative (SERI) of the Department of Science and Technology (DST/TM/SERI/ 2K11/115), India for financial support. The authors thank Prof. Ashok K Mishra and SAIF, IIT Madras for TCSPC facilities. All the authors also thank Department of Chemistry, IIT Madras for other instrumental facilities.

\section{References}

1. Bürckstümmer H, Tulyakova E V, Deppisch M, Lenze M R, Kronenberg N M, Gsänger M, Stolte M, Meerholz K and Würthner F 2011 Efficient solution-processed bulk heterojunction solar cells by antiparallel supramolecular arrangement of dipolar donor-acceptor dyes Angew. Chem. Int. Ed. $\mathbf{5 0} 11628$

2. Carsten B, Szarko J M, Son H J, Wang W, Lu L, He F, Rolczynski B S, Lou S J, Chen L X and Yu L 2011 Examining the effect of the dipole moment on charge separation in donor-acceptor polymers for organic photovoltaic applications J. Am. Chem. Soc. 133 20468

3. Sun X, Liu Y, Xu X, Yang C, Yu G, Chen S, Zhao Z, Qiu W, Li Y and Zhu D 2005 Novel electroactive and photoactive molecular materials based on conjugated donoracceptor structures for optoelectronic device applications J. Phys. Chem. B 10910786

4. Deibel C, Strobel T and Dyakonov V 2010 Role of the charge transfer state in organic donor-acceptor solar cells Adv. Mater. 224097

5. Numata T, Murakami T, Kawashima F, Morone N, Heuser J E, Takano Y, Ohkubo K, Fukuzumi S, Mori Y and Imahori H 2012 Utilization of photoinduced chargeseparated state of donor-acceptor-linked molecules for regulation of cell membrane potential and ion transport J. Am. Chem. Soc. 1346092

6. Higashino T, Yamada T, Yamamoto M, Furube A, Tkachenko N V, Miura T, Kobori Y, Jono R, Yamashita K and Imahori H 2016 Remarkable dependence of the final charge separation efficiency on the donor-acceptor interaction in photoinduced electron transfer Angew. Chem. Int. Ed. 55629

7. Mallia A R, Salini P and Hariharan M 2015 Nonparallel stacks of donor and acceptor chromophores evade geminate charge recombination J. Am. Chem. Soc. 137 15604

8. Bard A J and Fox M A 1995 Artificial photosynthesis: Solar splitting of water to hydrogen and oxygen Acc. Chem. Res. 28141

9. Luo C, Guldi D, Imahori H, Tamaki K and Sakata Y 2000 Sequential energy and electron transfer in an artificial reaction center: Formation of a long-lived charge-separated state J. Am. Chem. Soc. 1226535

10. Ohashi M, Aoki M, Yamanaka K I, Nakajima K, Ohsuna T, Tani T and Inagaki S 2009 A periodic mesoporous organosilica-based donor-acceptor system for photocatalytic hydrogen evolution Chem. Euro. J. 1513041

11. Alsam A A, Aly S M, Usman A, Parida M R, Del Gobbo S, Alarousu E and Mohammed O F 2015 Bimolecular excited-state electron transfer with surprisingly longlived radical ions J. Phys. Chem. C 11921896 
12. Suneesh C V and Gopidas K R 2009 Long-lived photoinduced charge separation in flexible 9, 10-bis (phenylethynyl) anthracene- phenothiazine dyads $J$. Phys. Chem. C 1131606

13. Rakhi A M and Gopidas K R 2015 Generation of long-lived methylviologen radical cation in the tripletstate mediated electron transfer in a $\beta$-cyclodextrin based supramolecular triad Chem. Phys. Lett. 618 192

14. de la Escosura A, Martinez Diaz M V, Guldi D M and Torres T 2006 Stabilization of charge-separated states in phthalocyanine- fullerene ensembles through supramolecular donor-acceptor interactions J. Am. Chem. Soc. 1284112

15. Wolff C and Grätzel M 1977 Photoinduced electron transfer from chlorophyll-a to duroquinone in micellar solutions, charge separation through local electrostatic fields Chem. Phys. Lett. 52542

16. Kim Y, Das A, Zhang H and Dutta P K 2005 Zeolite membrane-based artificial photosynthetic assembly for long-lived charge separation J. Phys. Chem. B 109 6929

17. Kashiwagi Y, Ohkubo K, McDonald J A, Blake I M, Crossley M J, Araki Y, Ito O, Imahori $\mathrm{H}$ and Fukuzumi S 2003 Long-lived charge-separated state produced by photoinduced electron transfer in a zinc imidazoporphyrin-C60 dyad Org. Lett. 52719

18. Bhattacharyya A, Malakar P and Prasad E 2017 Long lived charge separated states in vinylbenzonitrile substituted derivatives of pyrene and anthracene J. Photochem. Photobiol. A Chem. 34088

19. Sun L and Goerner, H 1993 Excited-state properties of trans-1-(9-anthryl)-2-(4-R-phenyl) ethylenes with electron-donating and-accepting substituents $[\mathrm{R}=\mathrm{N}$ $\left(\mathrm{CH}_{3}\right)$ 2, $\mathrm{OCH} 3, \mathrm{CH}_{3}, \mathrm{Br}, \mathrm{CN}$, and $\left.\mathrm{NO}_{2}\right]$ J. Phys. Chem. 9711186

20. Aloisi G G, Elisei F, Latterini L, Passerini M and Galiazzo G 1996 (E)-9-styrylanthracene derivatives and their interactions with electron donors and acceptors. Fluorimetric and flash photolytic studies J. Chem. Soc. Faraday Trans. 923315

21. Görner H 1999 Photoprocesses in 4-nitro-and 2, 4dinitro-substituted trans-1-styrylnaphthalene, trans-9styrylanthracene and related systems J. Photochem. Photobiol. A Chem. 12615

22. Görner H 2002 Photoreduction of trans-4-R-4/nitrostilbenes with R: OMe, $\mathrm{H}$ and NO 2 by di-and trialkylamines in polar media Phys. Chem. Chem. Phys. 4482
23. Bortolus P, Galiazzo G, Gennari G and Monti S 2002 Photochemistry of (E)-1-(9-anthryl)-2-(4-nitrophenyl) ethene in the presence of aliphatic amines: H-bonding and charge-transfer effects Photochem. Photobiol. Sci. 1 412

24. Paul A and Samanta A 2007 Photoinduced electron transfer reaction in room temperature ionic liquids: A combined laser flash photolysis and fluorescence study J. Phys. Chem. B 1111957

25. Okada T, Karaki I and Mataga N 1982 Picosecond laser photolysis studies of hydrogen-atom transfer reaction via heteroexcimer state in pyrene-primary and pyrenesecondary aromatic amine systems: Role of hydrogenbonding interaction between amino group of donor and $\pi$ electrons of acceptor in the heteroexcimer J. Am. Chem. Soc. 1047191

26. Lakowicz J R 2006 Principles of fluorescence spectroscopy $3^{\text {rd }}$ edn. (New York: Springer)

27. Nad S and Pal H 2000 Electron transfer from aromatic amines to excited coumarin dyes: Fluorescence quenching and picosecond transient absorption studies J. Phys. Chem. A 104673

28. Shirota H, Pal H, Tominaga K and Yoshihara K 1998 Substituent effect and deuterium isotope effect of ultrafast intermolecular electron transfer: Coumarin in electrondonating solvent J. Phys. Chem. A 1023089

29. Kavarnos G J 1993 Fundamentals of Photoinduced Electron Transfer (Berlin: VCH Publications)

30. D'Souza F, Chitta R, Ohkubo K, Tasior M, Subbaiyan N K, Zandler M E, Rogacki M K, Gryko D T and Fukuzumi S 2008 Corrole- fullerene dyads: Formation of longlived charge-separated states in nonpolar solvents J. Am. Chem. Soc. 13014263

31. Vauthey E and Phillips D 1990 Viscosity effect on the rate of back electron transfer within a short-lived exciplex Chem. Phys. 147421

32. Bhattacharyya A, Mukherjee S, Chadha A and Prasad E 2018 Diffusion of solvent-separated ion pairs controls back electron transfer rate in graphene quantum dots $J$. Phys. Chem. C 12215819

33. Brandes K K and Gerdes R 1967 The influence of 1, 4dioxane and tetrahydrofuran as solvents on the stability and the solvation of negative ions of the potassium compounds of naphthalene and anthracene J. Phys. Chem. 71 508

34. Zahradnik R and Carsky P 1970 Conjugated radicals. II. Semiempirical calculations of electronic spectra of radical anions derived from alternant hydrocarbons $J$. Phys. Chem. 741240 